\title{
Currículum, vida y cultura: una aproximación filosófica ${ }^{1}$
}

Gustavo Adolfo Esparza Urzúa

\section{Entre la vida natural cotidiana y las técnicas curriculares}

$\mathrm{E}^{\mathrm{s}}$

1 objetivo del presente trabajo es reflexionar acerca de la relación entre el currículum -en tanto que instrumento pedagógico-, la vida cotidiana -como marco general de desarrollo-, y la cultura -como producto curricular. Mi interés se centra en el vínculo que existe entre el diseño de planes y programas y los fundamentos que favorecen que el currículo opere como agente constructor de la vida cultural.

El problema que se asume es simple, considerando que todos los seres humanos de modo natural evolucionamos y adoptamos un conjunto de acciones específicas que nos permiten solventar distintos problemas, ¿por qué es necesario el desarrollo de programas educativos que fomenten conductas que, en principio, podemos considerar no-naturales? Centremos el problema: la pertinencia y necesidad de construir planes y programas técnicos que estén encaminados al desarrollo de habilidades específicas que parece satisfacen más a ciertos intereses grupales que a las propias necesidades cotidianas, conlleva a la valoración del currículum como instrumento de articulación del poder. En el trabajo ya clásico de Bordieu y Passeron (1996), La reproducción. Elementos para una teoría del sistema de enseñanza, se sostiene que el instrumental pedagógico desarrollado por la escuela se convierte en un promotor y conservador de los intereses sociales, lo que genera una violencia simbólica al establecer un marco didáctico general de formación en lugar de un marco didáctico diferenciador en el cual se promuevan las capacidades individuales.

1 Agradezco los comentarios y sugerencias de algún lector anónimo. Su reflexión sobre el concepto de currículum me permitió revisar ciertos comentarios que, de no haber corregido, hubiera sido imprecisa la tesis que quería plantear; considero que, incluidas las sugerencias, la idea central que propuse se mantiene. También mis agradecimientos al High School del Centro Escolar El Encino por el apoyo y recursos a la redacción del presente texto. En este centro desarrollé parte de las ideas que aquí presento.
Aunque, efectivamente, el currículum se encamina a la promoción de las conductas educativas $\mathrm{y}$, en ese sentido, se puede considerar como instrumento de articulación del poder, se sostiene que una revisión de sus fundamentos permite relacionar: i) la vida cotidiana como hecho natural, y ii) los instrumentos técnico-pedagógicos que, aunque operan como recursos para la consecución de fines educativos, armonizan con los fines perseguidos por una cultura en general. Es decir, los principios mediante los cuales un proyecto formativo transforma a la sociedad no deben ser considerados como medios de control, sino como una necesidad natural de guía y orientación. El currículum, en este sentido, se ofrece como el instrumental técnico que permite el logro de ciertas conductas operativas que no sería posible alcanzar de ningún otro modo.

\section{El currículum como productor y promotor de la vida social}

El currículum, como instrumento y órgano pedagógico, ha sido caracterizado por los distintos teóricos curriculares como un recurso a través del cual es posible la vinculación y promoción de los objetivos y fines educativos. Por ahora, no podemos distinguir por qué un instrumento que se propone favorecer conductas sociales o culturalmente cotidianas debe considerarse como un instrumento promotor de lo 
« El currículum, en este sentido, se

ofrece como el instrumental técnico que

permite el logro de ciertas conductas

operativas que no sería posible alcanzar

de ningún otro modo. $\gg$ cotidiano. Lo que sí se puede establecer es que el currículum ha sido caracterizado como un "instrumento funcional de la educación" (Tyler, 1973: 9). Para Ralph Tyler, los "fines que desea alcanzar la escuela" son el punto de partida para la organización de programas educativos; sin embargo, el mismo autor también pregunta si estos fines se buscan conscientemente o son cuestiones de "preferencia personal de ciertos individuos o grupos [...] en última instancia, son cuestión de preferencia personal y, en consecuencia, dependen de los juicios de valor de las autoridades docentes. Por ello hace falta una filosofía amplia de la educación que guíe en la formulación de esos juicios" (Tyler, 1973: 10).

Estos señalamientos de Tyler establecen un problema central en la historia del currículum: ¿qué tipo de filosofía se debe tener en cuenta a la hora del diseño de actividades educativas?, y lo que es aún más complejo: ¿es necesaria una filosofía educativa para la construcción de un instrumento que tiene como finalidad la promoción social? Para Joseph Schwab (1970), la solución de esta problemática generó una concepción teórica a expensas de una visión práctica del currículum; por ello, para el autor, era claro que el sentido de lo curricular se había encaminado a resolver dilemas teóricos que, en apariencia, resolvían cuestiones relacionadas con el proceso educativo, pero conllevó a una desatención de las prácticas educativas que debían ser satisfechas por un plan de estudios. Como alternativa de solución, Schwab planteará la necesidad de reincorporar una metodología del diseño que estuviera encaminada a resolver acciones prácticas en lugar de fomentar conductas teóricas. Hay que resaltar, sin embargo, que el centro de la argumentación de este autor no está en la eliminación de la teoría para el diseño curricular, sino en la consideración de una "metateoría" que tuviese como objeto pensar el currículum desde teorías educativas, en lugar de teorías científicas alternativas que parecen no considerar el proceso educativo y de construcción curricular (Schwab, 1970: 33-39).
Este planteamiento es retomado por Stephen Kemmis (1986), al considerar que "el problema central de la teoría del currículum debe ser entendido como el doble problema de las relaciones entre la teoría y la práctica, por un lado y el de las relaciones entre educación y sociedad, por otro" (p. 30. Énfasis en el original). Para este autor, entonces, el dilema del currículum se encuentra en las "interpretaciones" de dicha relación, ya que el currículo no sólo promueve entre los miembros de una sociedad un sistema de creencias, costumbres y prácticas cotidianas, sino que el propio programa educativo representa el conjunto de valores y tradiciones de un entorno cultural; es decir, un plan curricular traduce los modos en que se debe vincular la concepción ideal pensada para una sociedad o teoría curricular con el conjunto de tradiciones y actividades cotidianas de una sociedad o práctica curricular. Por ello, para este autor, una teoría curricular tiene como centro de reflexión el “problema de la representación” (Kemmis, 1986: 30).

Este problema representacional se puede apreciar más claramente en el trabajo de César Coll (1991:21), Psicología y currículum, quien, como parte de la "búsqueda de un marco curricular común que tenga en cuenta las características de la enseñanza obligatoria, [debe] traducir [los principios pedagógicos propuestos por el estado] en normas de acción, en prescripciones educativas, con el fin de elaborar un instrumento útil y eficaz para la práctica pedagógica". Para Coll, entonces, el currículum es un "eslabón" que vincula los principios pedagógicos generales con las prácticas operativas tradicionales.

Bajo estas dimensiones, se puede apreciar que el intento por vincular el currículum con su práctica, en no pocas ocasiones, ha desembocado en una "disonancia pedagógica”; es decir, en la construcción de planes educativos suele no existir una vinculación entre los términos didácticos propuestos para el desarrollo de las distintas habilidades dentro del aula, y los propios principios curriculares que se proponen para normar las acciones docentes. Gaspar Zavala y Gustavo Esparza (2015: 7) han resaltado este aspecto diciendo que "la teoría curricular, en muchos de los casos, no siempre se desarrolla en la docencia generando disonancias pedagógicas, lo que exige una revisión crítica para mediar entre el aula, la planeación y el aprendizaje significativo como centro".

El esfuerzo se debe centrar, según estos autores, en la promoción didáctica de las conductas que permitan a los estudiantes desarrollar habilidades 
que favorezcan la solución de los problemas a los que el individuo se enfrentará durante su vida en comunidad. El interés, por tanto, insiste en el reconocimiento de que el currículum debe promover acciones culturales que permitan el cumplimiento de las tareas a las que debe responder el individuo en comunidad. En este punto, entonces, se debe preguntar: ¿bajo qué mecanismos es posible establecer que el currículum opera como instrumento de promoción cultural?

\section{La vida social y sus marcos e instrumentos culturales de reproducción}

Para el análisis de este punto, traeré a consideración la filosofía de la cultura propuesta por Ernst Cassirer (1998), desarrollada en el marco de su Filosofia de las formas simbólicas (FFs). La tesis central de este filósofo neokantiano es que la filosofía clásica y medieval consideró que el estudio de la realidad se constituía bajo marcos sustanciales, en lugar de considerar los marcos funcionales o relacionales en los cuales se construye el conocimiento del mundo; es decir, el conocimiento de la realidad no se desarrolla de modo dicotómico (ser o no-ser), sino bajo marcos dialécticos en los que las dualidades interaccionan para la organización de formas simbólicas de conocimiento (Cassirer, 1998: 2012).
Toda la tarea que debe enfrentar una filosofía de la cultura se traduce en la investigación de los mecanismos que hacen posible la vinculación entre los aspectos más variados y que, en apariencia, se ofrecen como dualidades opuestas. Así, la subjetividad y la objetividad, la singularidad y la universalidad, vida y cultura, entre otras, se constituyen como antítesis básicas para la organización de una investigación crítica. A partir de esta consideración, Cassirer planteará que el resultado no es traducible a la formación de puntos, de acuerdo en los que las partes estudiadas encuentran una armonía constituida por un principio regulador, sino que se encuentran formas simbólicas específicas que revelan, no una formación cultural que representa las distintas fuerzas en interacción, sino las formas de vida mismas. Toda formación simbólica, en última instancia, es la realidad en la que nos desarrollamos y existimos, pero ahora en lugar de buscarla directamente, la entendemos por medio de sus refracciones y órganos espirituales a través de los cuales se revela (Cassirer, 1998).

Cassirer, entonces, comprenderá que toda forma simbólica cumple los siguientes criterios: 1) son recursos de vinculación entre el objeto y el sujeto; 2) son recursos de mediación para el conocimiento de la realidad y la vida; 3) son productos

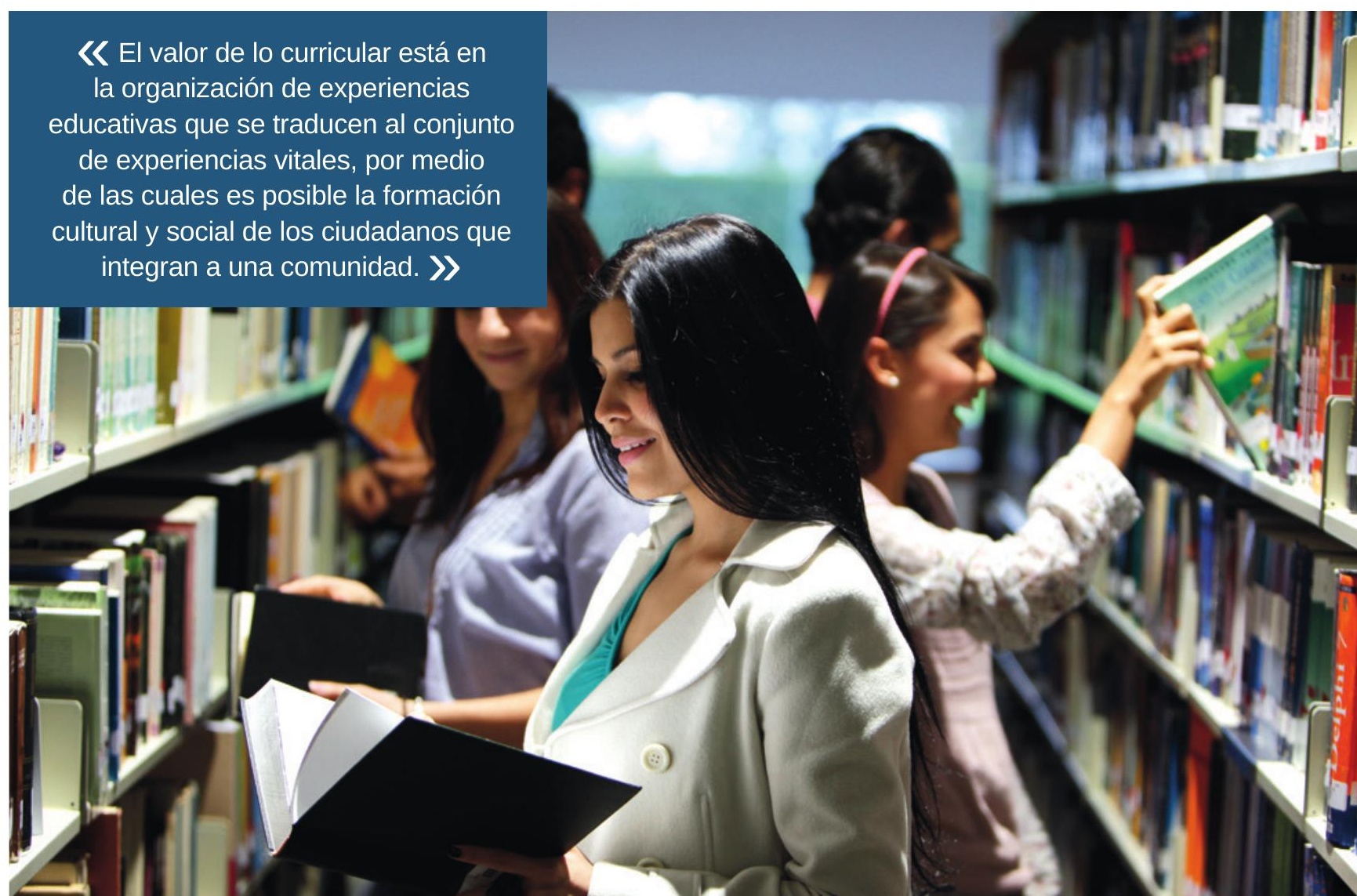


humanos toda vez que el conocimiento es una facultad o poder del ser humano; 4) refieren a distintos niveles de interacción cultural dependiendo de la relación que cumplan (expresiva, representativa o simbólica), (Esparza, 2017).

\section{Vida cotidiana y cultura: una interrelación curricular}

Hasta ahora se ha sostenido que el currículum opera como promotor de la vida cultural, toda vez que ofrece un programa organizado para el fomento de los intereses sociales, por lo que éste se constituye no sólo como un instrumento de reproducción dogmático, sino como una actividad necesaria para la conservación y promoción de la cultura misma. $\mathrm{Si}$, en este sentido, se acepta que el interés de la vida en comunidad está centrado en la preservación y en el desarrollo de mecanismos de promoción, entonces se puede asumir que todo programa educativo mantiene una responsabilidad pedagógica y cultural.

Considerando aquí el conjunto de principios estipulados por Cassirer y aplicados al problema curricular, se puede aducir lo siguiente sobre el currículo: a) es un recurso de vinculación entre el sujeto y el entorno cultural; b) es un recurso de mediación entre la realidad y la vida en comunidad; c) es un produc- to pedagógico que tiene como finalidad la promoción de los valores comunitarios; d) permite el desarrollo en distintos niveles y promoción conductual y sociocultural. De este modo, entonces, se puede sostener que el currículum es una práctica pedagógica que, por principio, no está constituida o reducida a la atención de las necesidades políticas o de intereses grupales, sino al desarrollo y promoción de las acciones que a la comunidad y a quienes participan y viven en ella les convenga. Toda desviación de estos principios básicos no constituye la razón de ser del currículum, sino una práctica profesional ajena a la planeación educativa, pero una evaluación ética de lo curricular corresponde a otra reflexión.

\section{Conclusión}

En el presente trabajo se reflexionó sobre la relación que mantiene el currículo y la vida cultural de las sociedades. Se sostuvo que el papel central de una planeación educativa está centrado en la preservación de los valores y principios culturales. Se hizo notar que el valor de lo curricular está en la organización de experiencias educativas que se traducen al conjunto de experiencias vitales, por medio de las cuales es posible la formación cultural y social de los ciudadanos que integran a una comunidad.

\section{Fuentes de consulta}

Bordieu, P. y Passeron, J. (1996). La reproducción. Elementos para una teoría del sistema de enseñanza. Ciudad de México: Fontamara.

Cassirer, E. (1998). Filosofía de las formas simbólicas. Fenomenología del conocimiento. Traducción de Fernando Morones. Ciudad de México: Fondo de Cultura Económica.

Cassirer, E. (2012). Antropología filosófica. Una introducción a la filosofía de la cultura. Ciudad de México: Fondo de Cultura Económica.

Coll, C. (1991). Psicología y currículum. Barcelona: Paidós.

Esparza, G. (2017). Ernst Cassirer: Fenomenología del autoconocimiento en el marco de la tensión vivencial

y espiritual. Agora: papeles de Filosofia, 36(1), 149-169.

Kemmis, S. (1986). El currículum: más allá de la teoría de la reproducción. Madrid: Morata.

Schwab, J. (1970). The practical: a language for curriculum. Washington: National Education Association Center for the Study of Instruction.

Tyler, R. (1973). Principios básicos del currículo. Buenos Aires: Troquel.

Zavala, G. y Esparza, G. (2015). ¿Marco curricular de enseñanza o aprendizaje significativo? Una visión conciliadora dentro del aula. Docere, 13, 7-10. México: Universidad Autónoma de Aguascalientes. 